\title{
Global Warming, Cyclone Damages, and the Issue of Sustainable Tourism in Southeast Asia
}

\author{
TAM BANG VU \\ University of Hawaii-Hilo - tamv@hawaii.edu \\ ERIC IKSOON IM \\ University of Hawaii-Hilo - eim@hawaii.edu
}

\section{ARTICLE INFO ABSTRACT}

Article history:

Received:

Dec. 102015

Received in revised form:

Dec. 122015

Accepted:

Dec. 302015

Keywords:

Southeast Asia, cyclone damages, sustainable tourism, feedback effect.
This paper studies the feedback effect between damages caused by cyclones and unsustainable tourism in Southeast Asia. The data are constructed based on the Annual Tropical Cyclone Reports from the United States National Climatic Data Center website for the period of 1995-2013. Establishing a cyclone damage index by combining the maximum speed when each cyclone goes through a region and characteristics of each region affected by cyclones in Southeast Asia, we first attempt to quantify the two-way causality between these cyclones and the proportion of tourist arrivals per capita. We then analyze differences among the affected countries compared to the aggregate effects. Based on the results, policy suggestions for sustainable tourism are provided in order to mitigate the cyclone damages. 


\section{Introduction}

The past twenty years have witnessed rapid growth in tourist arrivals in Southeast Asia (SEA). However, the same period has also observed rises in the intensity of the cyclones in the SEA region even though the number of the events has decreased slightly. Figure 1 demonstrates this increasing frequency of the cyclones with the speed greater than 100 knots (185 km per hour $/ \mathrm{kph})$ that occurred in the Pacific and Indian Oceans in general and the ones landed in the SEA countries in particular over the past forty years. There are concerns that unsustainable tourism contributes in part to the global warming due to greenhouse-gas emissions and environmental pollution. This rising temperature is believed to be one of the causes for the rising intensity of the cyclones and the increase in cyclone damages worldwide.

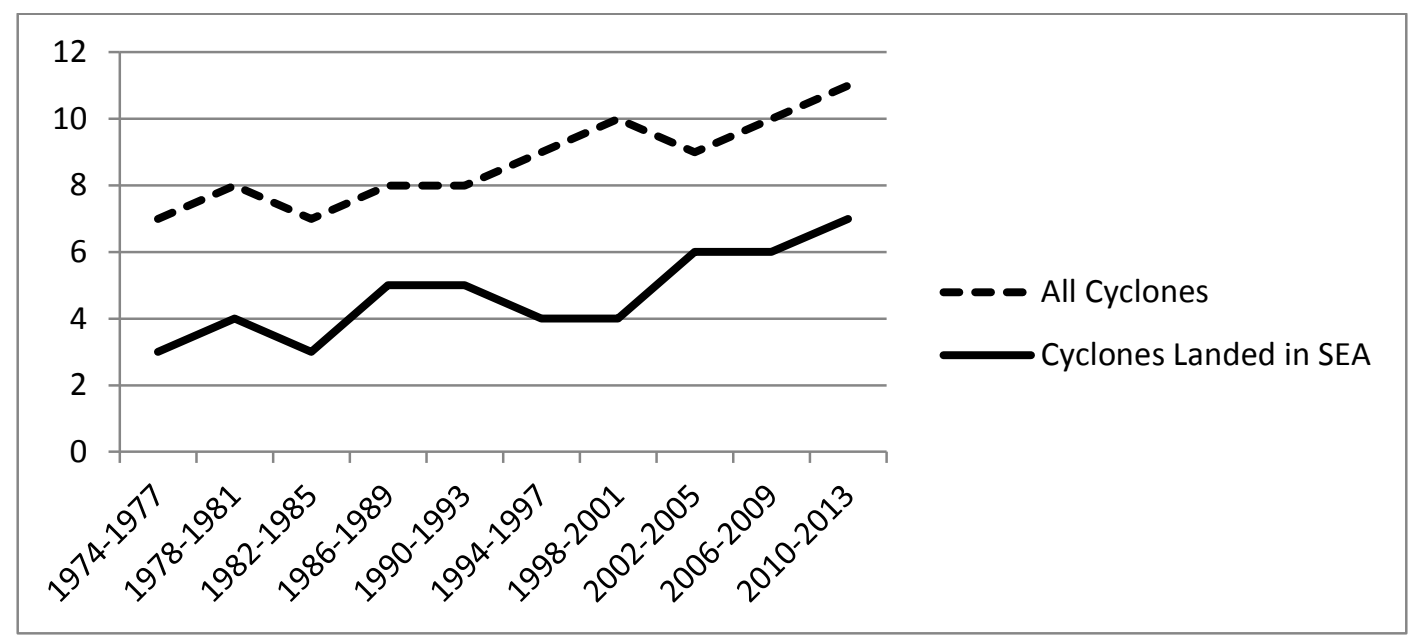

Figure 1. Number of cyclones greater than 100 knots in Pacific and Indian Oceans Sources: US National Climatic Data Center, US National Oceanic and Atmospheric Administration

Given the potential destruction caused by cyclones and the danger of unsustainable tourism in addition to the inconsistent results in the existing literature, it is crucial to study the possible feedback effects between cyclones and unsustainable tourism in order to mitigate cyclone damages. This paper investigates the impact of cyclones from the Pacific and Indian Oceans on tourism in SEA and the possible reversed impact of unsustainable tourism on cyclone damages. A panel dataset on storm frequency and intensity in SEA is constructed based on information provided by the US National Oceanic and Atmospheric Administration (NOAA). We first set out to find the impact 
of these disasters on aggregate ratio of tourist arrivals to population in these countries. Next, we examine country differences which are potentially caused by country specific characteristics. Finally, we propose prevention measures through sustainable tourism.

\section{Theoretical framework}

Before 2006 literature on disasters could not find the link between rising temperature and the increasing intensity of the cyclones or the cyclone damages. One of the first papers that provided concrete results was authored by Michaels et al. (2006). These scholars found that there is a threshold of sea-surface temperature (SST) where a tropical storm develops into a typhoon. Specifically, when the SST is exceeding $28.25^{\circ} \mathrm{C}$, the link between the rising temperature and the increasing intensity of the cyclones becomes clear. Another paper that found evidence is written by Knutson et al. (2007), who used simulation technique and predicted that the intensity of the Pacific cyclones would increase due to global warming.

Bender et al. (2010), in a similar paper, also confirmed the link between rising temperature and the intensity of the Atlantic cyclones. Overall, Mendelsohn et al. (2012) pointed out that climate change increases the frequency of high-intensity storms in selected ocean basins depending on the climate model in each region. Most recently, Estrada et al. (2015) showed the intensity of hurricanes as well as the damages due to cyclones both increase with the rising temperature in the North Atlantic basin. This tendency is evident even for the US, one of the countries best prepared for countering cyclone damages. Specifically, in 2005 between 2 billion and 14 billion US dollars of the cyclone damages were attributed to climate change in the country.

Regarding the SEA region, Chang (2010) asserted that there is enough evidence to show the link between high temperature and the rising frequency of the super storms in SEA. Since Michaels et al. (2006) have already stipulated the threshold of $28.25^{\circ} \mathrm{C}$, it is easy to understand Chang's result for SEA, which likely has SST exceeding this threshold. The article also carried out a case study of an anomalous storm event in Southeast Asia as an example of the link between global warming and increasing cyclone damages: cyclone Vamei and the extremely high rainfall caused by global warming in December 2006 in Malaysia. The author then called for increasing preparedness to face climate changes. 
Cyclones cause substantial damages to tourism. Most people still remember Super Typhoon Haiyan, which killed 6,340 people in the Philippines and destroyed most of the tourist facilities on November 8, 2013, before landing in Vietnam on November 11. Although it had weakened significantly, Haiyan still packed heavy rain and winds of 110 $\mathrm{kph}$ in North Vietnam, uprooting hundreds of trees and tearing roofs off homes. Recently, hundreds of tourists were stranded on islands in Quang Ninh Province as Tropical Storm Kujira made its landfall on June 24, 2015. While 172 tourists were evacuated by ships at Quan Lan Island, shipping was halted due to high wind on Co To Island, stranding about 500 tourists.

Nevertheless, many authors found that the long-term effects of cyclones are not clear although their short-term effects are negative. The impacts are also more severe in developing countries than in developed ones. In addition, the research results are not consistent. Bluedorn (2005) studied cyclone activities in developing countries of the Central American and Caribbean region, showing that the median hurricanes will cause output to fall by 0.3 percent, while Strobl (2008), examining the same region, suggested a reduction in output by 0.8 percent. Coffman and Noy (2009) gave a detailed narration of Hurricane Iniki in Hawaii and found that its shot-term effect on the Hawaiian economy is small and that its long-term effect is insignificant.

Concerning tourism, Hitchcock and Parnwell (2010) discussed the historical development of tourist arrivals in SEA and their contribution to the regional economies. They indicated that the role of tourism in economic growth in SEA has been increasing over the past twenty years. Mazumder et al. (2013) summarized six reasons that make tourism important for the SEA countries. First, tourism yields foreign exchange earnings used to import other goods. Second, tourism utilizes resources consistent with the country's factor endowment. Third, tourism increases employment in the host country. Fourth, tourism encourages improvements in the infrastructure. Fifth, tourism fosters technical transfers and knowledge spillovers. Finally, tourism creates linkages among other sectors, such as agriculture, manufacture, and services.

However, unsustainable tourism can cause damages to the economy. UNESCO's "Save the Ifugao Terraces Movement" Team (2008) emphasized that unsustainable tourism can destroy the environment in the host countries. Hitchcock and Parnwell (2010) devoted three chapters on unsustainable tourism, including environmental degradation. Le (2014) also pointed out that tourists can cause greater pollution and 
landscape damages. In addition, the construction of new resorts and hotels are causing deforestation and increasing wastes. These activities might contribute in part to the rise in overall temperature due to tourists' excessive use of air conditioners that increases greenhouse-gas emissions and causes the increase in solid wastes raising the carbondioxide proportion in the air.

Hershberger (2014) outlined six challenges facing SEA tourism, namely endangered species conservation, air pollution, destruction of coral reefs, deforestation, water security, and disorganized urbanization. Ponnudurai (2015) analyzed the urgent issue of environmental degradation due to unsustainable tourism in SEA. The author illustrated the scientific forecasts that reveal a surge in heat extremes in the region due to greenhouse-gas emissions and increasing solid wastes. The paper predicted that these rising temperatures would lead to a significant increase in the maximum wind speed of cyclones making landfall in Southeast Asia and a rise in cyclone damages due to the subsequent heavy rains and flooding.

\section{Data}

Existing literature on the regional impact of cyclones often uses the number of hurricane events or their maximum observed Saffir-Simpson scale. In reality, a cyclone's destructive impact on each country is very different, depending on the maximum wind speed at each location and local characteristics of the region. In order to account for these differences, we construct a dataset for this study.

The original dataset on the number and intensity of the SEA cyclones is based on the Annual Tropical Cyclone Reports for the West Pacific, South Pacific, and Indian Oceans provided by the Joint Typhoon Warning Center (JTWC) of the NOAA that posted the information on the US National Climatic Data Center (NCDC) website for the period between 1995 and 2013. To our best knowledge, this is the most comprehensive source of cyclones for SEA.

In the West Pacific region, a cyclone with an estimated intensity of less than 34 knots (63 kph) is called a "Tropical Depression," the one between 34 knots (64 kph) and 63 knots (116 kph) is designated a "Tropical Storm." A cyclone with an estimated intensity between 64 knots $(117 \mathrm{kph})$ and 129 knots $(239 \mathrm{kph})$ is called a "Typhoon," while a cyclone of 130 knots $(240 \mathrm{kph})$ or greater is named a "Super Typhoon." In the Indian 
Ocean and South Pacific Ocean, JTWC labels all cyclones as "Tropical Cyclones," regardless of estimated intensity.

The JTWC's reports indicated no cyclone in Singapore and Brunei during 19952013, so these two countries are eliminated from this study. Data for East Timor are not comprehensive and therefore are also eliminated. Most of the cyclones that reached Laos and Cambodia made their landfalls in Central and South Central Vietnam, interrupting the flows of Vietnamese tourists to these two neighboring countries along the cyclone trails. For example, Typhoon Yvette (27W) landed in South Central Vietnam on October 26, 1995, and continued its trail to reach Cambodia on October 27. Similarly, Typhoon Fritz (22W) landed in Central Vietnam on September 25, 1997, reaching Laos on the same day and Cambodia on September 26. Hence, the impacts of cyclones on the tourist arrivals in Cambodia and Laos might still be significant although the cyclones had become weak once they reached these two countries. For this reason, Cambodia and Laos are included in the research.

Table 1 displays the distribution of the cyclones that went through the affected countries in SEA during 1995-2013 based on the JTWC reports. The table shows that the Philippines endures the highest frequency of cyclones with Vietnam coming in second, whereas Laos endures the least and Cambodia, the second least. A panel dataset on the cyclone-damage index in SEA is constructed based on the intensity of the cyclones and the population density in each location where a cyclone made its landfall.

\section{Table 1}

Distribution of cyclones in affected SEA countries during 1995-2013

\begin{tabular}{lccccc}
\hline Country & Total & Mean & Std. dev. & Max & Min \\
\hline Cambodia & 16 & 0.8421 & 0.5165 & 3 & 0 \\
Indonesia & 32 & 1.6842 & 0.7609 & 4 & 1 \\
Laos & 14 & 0.7368 & 0.4183 & 2 & 0 \\
Malaysia & 22 & 1.1579 & 0.6335 & 3 & 1 \\
Myanmar & 24 & 1.6842 & 0.5824 & 3 & 1 \\
Philippine & 93 & 4.8947 & 2.4549 & 14 & 3 \\
Thailand & 26 & 1.3684 & 0.7471 & 5 & 1 \\
Vietnam & 79 & 4.4159 & 2.1072 & 12 & 2 \\
\hline
\end{tabular}

Sources: US National Climatic Data Center, NOAA Website 
We use a proxy of financial destruction introduced by Emanuel (2005), who showed that the financial losses due to cyclones tend to rise roughly to the cubic power of maximum wind speed when the cyclone makes its landfall on a specific country. Hence, he suggested a simplified power index that can serve to measure the potential destructiveness of cyclones as follows:

$$
P I=\int_{t=0}^{T} V^{3} d t
$$

where $V$ is the maximum sustained velocity of the wind at the landfall, and $T$ is the lifetime of the storm as accumulated over time intervals $t$.

Granvorka and Strobl (2010) used a weight on each local characteristic to estimate the effect of hurricane on tourism in the Caribbean. To account for the different characteristics, they used the time varying population density of each location. The justification is that of two equally affected areas in terms of wind speed, the one where more people live is likely to endure more incurred damages. We combine the approach in Emanuel (2005) and the one in Granvorka-Strobl (2010) by expressing the damage index of cyclones in a country at time $t$ based on the total damage due to the $n=1,2, \ldots$, $N$ cyclones that affected county $i$ during this time when they make landfall in locations $j=1,2, \ldots, J$ as:

$$
D A M_{i, t}=\sum_{j=1}^{J} \sum_{n=1}^{N} w_{i, \mathrm{j}, \mathrm{n}, t} V_{\mathrm{j}, t}^{3}
$$

where $V$ is the maximum velocity of the wind due to storm $n$ observed in country $i$ at time $t$, and $w$ is the weight assigned according to the characteristic of the affected country in terms of population density at the landfall location.

Data on the number of tourist arrivals, infrastructure, education at all levels, and capital formation come from the World Development Indicators, posted on the World Bank Group website. Data on other variables are found on the US Department of Agriculture Website and International Monetary Fund (IMF) website. Since yearly data on tourism and the other variables are only available from 1995 to 2013, this is chosen as our estimation period. Table 2 presents descriptive statistics on tourism for the eight SEA countries affected by cyclones. 


\section{Table 2}

Tourist arrivals in eight SEA countries affected by cyclones

\begin{tabular}{ccccc}
\hline Period & $1995-1998$ & $1999-2003$ & $2004-2008$ & $2009-2013$ \\
\hline Country & Mean & Mean & Mean & Mean \\
\hline Cambodia & 246500 & 585400 & 1663400 & 3069200 \\
Std. dev. & 33071 & 170227 & 437739 & 827563 \\
Indonesia & 4787250 & 4889000 & 5386800 & 7564600 \\
Std. dev. & 394353 & 285071 & 536285 & 951677 \\
Lao PDR & 136500 & 206800 & 871600 & 1869000 \\
Std. dev. & 70638 & 32790 & 356705 & 481589 \\
Malaysia & 6592250 & 10959400 & 18541200 & 24737000 \\
Std. dev. & 874850 & 2156306 & 2816741 & 751750 \\
Myanmar & 413250 & 482000 & 678800 & 1094800 \\
Std. dev. & 146286 & 70470 & 42775 & 543546 \\
Philippines & 2045250 & 1960000 & 2797600 & 3881600 \\
Std. dev. & 203093 & 137525 & 350862 & 646486 \\
Thailand & 7333250 & 9863600 & 13234800 & 19643400 \\
Std. dev. & 371799 & 820146 & 1474876 & 4977454 \\
Vietnam & 1548500 & 2261800 & 3690600 & 5846200 \\
Std. dev. & 154161 & 320840 & 553646 & 1504221 \\
\hline
\end{tabular}

Source: World Development Indicators, World Bank Website

The table reveals Malaysia as the country with the most tourist arrivals, and Thailand stands as the second. While Laos has started with the lowest number of tourists and Cambodia, the second lowest during 1995-1998, they have the highest growth rates and so surpassed Myanmar by 2004.

Data on real exchange rate and consumer price index are from the database for international macroeconomic data, provided by the US Department of Agriculture Website. The real exchange rates are expressed relative to US exchange rate, which is 
normalized to unity. Inflation is measured by the consumer price index of each country. Data on interest rate are from IMF website.

\section{Methodology}

Obtaining the dataset on damage index (DAM) constructed in Section 2, we estimate a system of equations to account for the possible feedback effects among the variables:

$$
\begin{aligned}
& \operatorname{TOUR}_{i, t}=\alpha_{1} D A M_{\mathrm{i}, t}+\sum_{k=1}^{K} \alpha_{k} D A M_{\mathrm{i}, t-k}+\beta X_{i, t}+q_{i}+s_{t}+\varepsilon_{i, t} \\
& F E E D B C_{i, t}=\varphi Z_{i, t}+\sum_{l=1}^{L} \gamma_{l} Z_{\mathrm{i}, t-l}+v_{i}+w_{t}+\omega_{i, t}
\end{aligned}
$$

where TOUR is tourism and is estimated alternatively as the ratio of tourist arrivals to population or the growth rate of this ratio, $i$ is country index among SEA countries, $t$ is the time index measured in years. $k$ and $l$ are the number of lagged periods. $D A M$ is the damage index caused by the cyclones. $F E E D B C$ is any variable in the right-hand sides of the two equations that might cause feedback effects among the variables. $X$ and $Z$ are two vectors of potential control variables that might affect the dependent variables in the system. The last three variables in each equation are country specific effect, time specific effect, and idiosyncratic disturbances, respectively.

We perform the Variance Inflation Factors (VIF) test as discussed in Kennedy (2008), which recommended the elimination of any variable that has VIF greater or equal to 10 . After eliminating variables with high correlations using the VIF test, we perform the RAMSEY RESET test for omitted variables as discussed in Kennedy (2008). The pvalue for the test is 0.415 , implying that there is no important omitted variable.

We then perform Granger-causality tests as discussed in Kennedy (2008) to investigate the possible feedback effects among variables in the system. The t-statistics for tourism and the F-statistic for joint significance of the current and lagged values all indicate that TOUR does Granger-cause DAM. This is different from the assumption of the weak exogeneity of the disaster measures used in Skidmore and Toya (2002) that used aggregate disaster measures instead of cyclone damages. In addition, we find that there is a feedback effect between $D A M$ and growth rate of per capita income, which is one of the control variables. 
The Dickey-Fuller tests as proposed in Kennedy (2008) reveal that the series are stationary, and a Hausman test shows that a random effect is more appropriate than a fixed effect model. Hence, the random effect three stage least square estimations (RE3SLS) are employed instead of the panel VAR procedures. The Akaike Information Criteria procedures also show that the models with one lagged values are the most appropriate. Hence, System (4) of our structural equations can be expressed as:

$$
\begin{gathered}
\operatorname{TOUR}_{i, t}=\alpha_{1} \text { DAM }_{\mathrm{i}, t}+\alpha_{2} \text { DAM }_{\mathrm{i}, t-1}+\beta_{1} \text { PERCA }_{i, t}+\beta_{2} E X C_{i, t}+\beta_{3} I N F R A_{i, t}+q_{i}+s_{t}+\varepsilon_{i, t} \\
D A M_{\mathrm{i}, t}=\theta_{1} \text { TOUR }_{i, t}+\theta_{2} \text { TOUR }_{i, t-1}+\lambda_{1} P E R C A_{i, t}+\lambda_{2} E D U_{i, t}+\lambda_{3} I N F R A_{i, t}+r_{i}+u_{t}+e_{i, t}
\end{gathered}
$$

PERCA $_{i, t}=\kappa_{1} D A M_{\mathrm{i}, t}+\kappa_{2} D A M_{\mathrm{i}, t-1}+\varphi_{1} \operatorname{TOUR}_{i, t}+\varphi_{2} I N I T_{i, t}+\varphi_{3} C A P+v_{i}+w_{t}+\omega_{i, t}$

where $P E R C A$ is growth rate of per capita income, $E X C$ real exchange rates, INFRA infrastructure, $E D U$ education, INIT the initial value of per capita income, and $C A P$ capital formation.

Lagged dependent variables are used as instrumental variables (IVs), and the system generalized method of moments (SGMM), as discussed in Bond (2002), is employed to control for any problem caused by the lagged dependent variables. System (5) presents the reduced forms so that predicted values from the regression results of System (5) can be used as IVs for System (4):

$$
\begin{aligned}
& \text { PERCA }_{i, t}=\pi_{11} \text { PERCA }_{i, t-1}+\pi_{12} \text { EXC }_{i, t}+\pi_{13} \text { INIT }_{i, t}+\pi_{14} \text { INFRA }_{i, t}+e_{1 i, t} \\
& \text { TOUR }_{i, t-p}=\pi_{21} \text { TOUR }_{i, t-2}+\pi_{22} E C_{i, t}+\pi_{23} E D U_{i, t}++\pi_{24} I N F R A_{i, t}+e_{3 i, t} \\
& D A M_{\mathrm{i}, t-p}=\pi_{31} \text { DAM }_{\mathrm{i}, t-2}+\pi_{32} I N I T_{i, t}+\pi_{33} \text { CAP }_{i, t}+\pi_{34} I N F R A_{i, t}+e_{2 i, t}
\end{aligned}
$$

Having estimated System (5) using SGMM procedure for $\mathrm{p}=0$ and 1, we obtain predicted value of PERCA in Eq. 5.1 as the IV for PERCA in Eq. 4.1, predicted value of TOUR in Eq. 5.2 as the IV for TOUR in Eq. 4.2, and predicted value of DAM in Eq. 5.3 as the IV for DAM in Equations 4.1 and 4.3. System (4) is then estimated simultaneously to avoid simultaneity bias using the RE3SLS approach. 


\section{Results and discussions}

Table 3 reports the aggregate effects between SEA cyclones and tourism, TOUR, which is defined as the ratio of tourist arrivals to population (T-RATIO) or growth rate of this ratio (T-GROW). Panels (3a), (3b), and (3c) present the results for Equations 4.1, 4.2 , and 4.3 respectively. We also present the sums of the current and lagged values in the three panels, as well as the p-values for the tests of their significances. For example, the effect of $D A M$ on $T-R A T I O$ in the current period (short-term impact) is -0.22 , and the effect after one year (long-term impact) is -0.04 . The composite impact is $-0.26(=-$ $0.22-0.04$ ), and the p-value for this sum is 0.048 . This implies that a one percentage point increase in the damage index decreases the tourist-arrival ratio to population in SEA by 0.26 percentage points, and the effect is statistically significant. Similar interpretations are applied to the other variables.

Panel (3a) also reveals that the overall effect of $D A M$ on $T-G R O W$ in SEA is negative and weakly significant for the current value, whereas it is negative and statistically significant for the lagged value. The composite effect as shown by the sum of these two values is negative and significant, also implying an adverse impact of cyclones on the growth rate of tourist-arrival ratio to population.

Panel (3b) shows that the short-term effect of TOUR on DAM in SEA is not statistically significant, but the long-term effect is statistically significant: the sum of the current and lagged values for the tourist-arrival ratio to population is 0.16 , and the $\mathrm{p}$ value for this sum is 0.041 . The sum of the current and lagged values for the growth rate of tourist ratio is 0.13 , and the p-value for this sum is 0.032 . They imply that the rise in unsustainable tourism in SEA does increase the damage levels of the cyclones.

From Panel (3c) we see that the overall effects of $D A M$ on growth rate of per capita income $(P E R C A)$ are smaller than those effects on tourism although they are negative and statistically significant for the current value, insignificant for the lagged value, and the sum of these two values is negative and significant. These results are consistent with the results in literature on the effect of natural disasters on per capita income in general, and can be explained by increasing public investment in new capital after a cyclone strikes as an effort to mitigate the damages caused by the disasters. It can also be explained by the private sectors that try to redirect their resources to other high-returned investments to offset the losses in the tourism sector. 


\section{Table 3}

Aggregate effects of cyclones on tourism and feedback effects

\section{Panel (3a)}

Dependent variable: ratio of tourist arrivals to population or growth rate of this ratio

\begin{tabular}{lcccccc}
\hline & \multicolumn{3}{c}{ T-RATIO } & \multicolumn{3}{c}{ T-GROW } \\
\hline Variable & Current & Lag & Sum & Current & Lag & Sum \\
\hline DAM & $-0.22^{* *}$ & $-0.04^{*}$ & $-0.26^{* *}$ & $-0.03^{*}$ & $-0.12^{* *}$ & $-0.15^{* *}$ \\
& $(0.035)$ & $(0.097)$ & $(0.048)$ & $(0.076)$ & $(0.041)$ & $(0.034)$ \\
\hline PERCA & $0.13^{* *}$ & & $0.22^{* *}$ & & \\
& $(0.038)$ & & $(0.034)$ & & \\
\hline EXC & $0.06^{* *}$ & & $0.03 * *$ & & \\
& $(0.047)$ & & $0.043)$ & & \\
& $0.06^{* * *}$ & & $0.04 * *$ & $(0.018)$ & \\
INFRA & $(0.005)$ & & & & \\
& & & & & \\
\end{tabular}

\section{Panel (3b)}

Dependent variable: cyclone damages

\begin{tabular}{|c|c|c|c|c|c|c|}
\hline Variable & Current & Lag & Sum & Current & Lag & Sum \\
\hline \multirow[t]{2}{*}{ TOUR } & 0.02 & $0.14^{* *}$ & $0.16^{* *}$ & 0.01 & $0.12 * *$ & $0.13 * *$ \\
\hline & $(0.122)$ & $(0.036)$ & $(0.041)$ & $(0.218)$ & $(0.049)$ & $(0.032)$ \\
\hline \multirow[t]{2}{*}{ PERCA } & $0.12 * *$ & & & $0.06 * *$ & & \\
\hline & $(0.031)$ & & & $(0.029)$ & & \\
\hline \multirow[t]{2}{*}{ EDU } & $-0.04 * *$ & & & $-0.02 * *$ & & \\
\hline & $(0.043)$ & & & $(0.028)$ & & \\
\hline \multirow[t]{2}{*}{ INFRA } & $-0.02 * *$ & & & $-0.03 * *$ & & \\
\hline & $(0.035)$ & & & $(0.038)$ & & \\
\hline
\end{tabular}




\section{Panel (3c)}

Dependent variable: growth rate of per capita income

\begin{tabular}{|c|c|c|c|c|c|c|}
\hline Variable & Current & Lag & Sum & Current & Lag & Sum \\
\hline \multirow[t]{2}{*}{ DAM } & $-0.04 * *$ & 0.01 & $-0.03 * *$ & $-0.02 * *$ & 0.01 & -0.01 \\
\hline & $(0.022)$ & $(0.154)$ & $(0.019)$ & $(0.045)$ & $(0.218)$ & $(0.037)$ \\
\hline \multirow[t]{2}{*}{ TOUR } & $0.03 * *$ & & & $0.04 * * *$ & & \\
\hline & $(0.011)$ & & & $(0.000)$ & & \\
\hline INIT & $-0.03 *$ & & & $-0.01 *$ & & \\
\hline \multirow[t]{2}{*}{ CAP } & $0.54 * * *$ & & & $0.29 * * *$ & & \\
\hline & $(0.003)$ & & & $(0.006)$ & & \\
\hline \multicolumn{2}{|c|}{ Number of observations } & & & 144 & & \\
\hline \multicolumn{2}{|c|}{ p-value for the F-test of the model } & & & 0.000 & & \\
\hline \multicolumn{2}{|c|}{ Average RMSE } & & & 0.214 & & \\
\hline \multicolumn{2}{|c|}{$\mathrm{p}$-value for $\mathrm{AR}(1)$} & & & 0.216 & & \\
\hline \multicolumn{2}{|c|}{ p-value for $A R(2)$} & & & 0.542 & & \\
\hline \multicolumn{2}{|c|}{$\begin{array}{l}\text { p-value for heteroscedasticity } \\
\text { (White) test }\end{array}$} & & & 0.365 & & \\
\hline
\end{tabular}

Note: $* * *$, and $* * *$ denote significance levels of $10 \%, 5 \%$, and $1 \%$ respectively. The $\mathrm{p}$-values are in parentheses.

The signs and significance levels of the control variables in each panel of Table 3 are as expected. For example, an appreciation of the real exchange rate decreases tourist arrivals, whereas improved infrastructure attracts more tourists. Note that an appreciation (or depreciation) of the real exchange rate is represented by a decrease (or increase) in the domestic currency required to exchange for one US dollar. Hence, the estimated coefficients of EXC have positive signs (a data point on domestic currency with a higher value relative to the US dollars implies a depreciation of the domestic currency and increases tourist arrivals).

We then proceed to investigate the feedback effects of the two benchmark variables-DAM and TOUR - in each country. Seven dummies are generated for Cambodia (CAM), Indonesia (INDO), Laos (LAO), Malaysia (MAL), Myanmar 
(MYAN), the Philippines (PHIL), and Thailand (THAI). These dummies are interacted with the above benchmarks variables to form slope dummies for the study. Vietnam (VIET) is used as the base-group dummy.

Table 4 reports the results of the benchmark variables in three panels equivalent to those in Tables 3. The estimated coefficients of the original variables are for VIET. For the other countries the first column presents the estimated coefficients of each dummy, which is expressed as the comparative value of the dummy to VIET, whereas the second column presents the absolute values for each country by calculating the sum of each dummy coefficient and that of VIET. We then test for the significances of these sums and report their p-values in each panel.

\section{Table 4}

Feedback effect of cyclones and tourism in SEA: Individual countries

\section{Panel (4a)}

Dependent variable: ratio of tourist arrivals to population or growth rate of this ratio

\begin{tabular}{lllll}
\hline & \multicolumn{2}{c}{ T-RATIO } & T-GROW \\
\hline Variable & Comparative & Absolute & Comparative & Absolute \\
\hline DAM (VIET) & & $-0.24^{* * *}$ & & $-0.14^{* *}$ \\
& & $(0.009)$ & $0.10^{* *}$ & $(0.026)$ \\
\hline CAM & $0.14^{* *}$ & $-0.07^{*}$ & $(0.031)$ & $-0.04^{*}$ \\
& $(0.044)$ & $(0.065)$ & $0.02^{* *}$ & $-0.075)$ \\
\hline INDO & $0.07^{* *}$ & $-0.17^{* *}$ & $(0.045)$ & $(0.033)$ \\
\hline LAO & $(0.028)$ & $(0.032)$ & $0.09^{* *}$ & $-0.05^{*}$ \\
& $0.18^{* *}$ & $-0.06^{*}$ & $(0.035)$ & $(0.064)$ \\
\hline MAL & $(0.048)$ & $(0.079)$ & $0.05^{* *}$ & $-0.09^{* *}$ \\
& $0.12^{* *}$ & $-0.12^{* *}$ & $(0.034)$ & $(0.043)$ \\
\hline MYAN & $(0.042)$ & $(0.039)$ & $0.03^{* *}$ & $-0.11^{* *}$ \\
& $0.08^{* *}$ & $-0.16^{* *}$ & $(0.046)$ & $(0.035)$ \\
\hline PHIL & $(0.031)$ & $(0.026)$ & $-0.15^{* * *}$ & $-0.29^{* * *}$
\end{tabular}




\begin{tabular}{lcccc}
\hline & \multicolumn{2}{c}{ T-RATIO } & \multicolumn{2}{c}{ T-GROW } \\
\hline Variable & Comparative & Absolute & Comparative & Absolute \\
\hline \multirow{2}{*}{ THAI } & $(0.002)$ & $(0.000)$ & $(0.006)$ & $(0.008)$ \\
& $-0.03^{* *}$ & $-0.27^{* *}$ & $-0.01^{* *}$ & $-0.15^{* *}$ \\
& $(0.024)$ & $(0.038)$ & $(0.041)$ & $(0.023)$ \\
\hline
\end{tabular}

\section{Panel (4b)}

Dependent variable: cyclone damages

\begin{tabular}{|c|c|c|c|c|}
\hline Variable & Comparative & Absolute & Comparative & Absolute \\
\hline \multirow[t]{2}{*}{ TOUR (VIET) } & & $0.14 * *$ & & $0.12 * *$ \\
\hline & & $(0.027)$ & & $(0.032)$ \\
\hline \multirow[t]{2}{*}{ CAM } & $0.03 * *$ & $0.17 * *$ & $0.03 *$ & $0.15^{* *}$ \\
\hline & $(0.035)$ & $(0.047)$ & $(0.044)$ & $(0.036)$ \\
\hline \multirow[t]{2}{*}{ INDO } & $0.03 * *$ & $0.17 * *$ & $0.02 * *$ & $0.14 * *$ \\
\hline & $(0.025)$ & $(0.032)$ & $(0.046)$ & $(0.021)$ \\
\hline \multirow[t]{2}{*}{ LAO } & $0.04 * *$ & $0.18 * *$ & $0.02 * *$ & $0.14 * *$ \\
\hline & $(0.025)$ & $(0.049)$ & $(0.034)$ & $(0.026)$ \\
\hline \multirow[t]{2}{*}{ MAL } & -0.01 & $0.14 * *$ & 0.01 & $0.12 * *$ \\
\hline & $(0.274)$ & $(0.027)$ & $(0.396)$ & $(0.032)$ \\
\hline \multirow[t]{2}{*}{ MYAN } & $0.05 * *$ & $0.19 * *$ & $0.04 * *$ & $0.16^{* *}$ \\
\hline & $(0.039)$ & $(0.028)$ & $(0.026)$ & $(0.033)$ \\
\hline \multirow[t]{2}{*}{ PHIL } & $0.07 * *$ & $0.21 * *$ & $0.06 * *$ & $0.17 * *$ \\
\hline & $(0.031)$ & $(0.046)$ & $(0.032)$ & $(0.024)$ \\
\hline \multirow[t]{2}{*}{ THAI } & -0.01 & $0.14 * *$ & 0.01 & $0.12 * *$ \\
\hline & $(0.405)$ & $(0.027)$ & $(0.621)$ & $(0.032)$ \\
\hline
\end{tabular}




\section{Panel (4c)}

Dependent variable: growth rate of per capita income

\begin{tabular}{|c|c|c|c|c|}
\hline Variable & Comparative & Absolute & Comparative & Absolute \\
\hline \multirow[t]{2}{*}{ DAM (VIET) } & & $-0.06^{* *}$ & & $-0.02 * *$ \\
\hline & & $(0.035)$ & & $(0.041)$ \\
\hline \multirow[t]{2}{*}{ CAM } & -0.008 & $-0.06 * *$ & 0.006 & $-0.02 * *$ \\
\hline & $(0.217)$ & $(0.035)$ & $(0.386)$ & $(0.041)$ \\
\hline \multirow[t]{2}{*}{ INDO } & $0.015^{*}$ & $-0.045^{* *}$ & $0.008^{*}$ & $-0.012 * *$ \\
\hline & $(0.079)$ & $(0.049)$ & $(0.064)$ & $(0.035)$ \\
\hline \multirow[t]{2}{*}{ LAO } & 0.005 & $-0.06^{* *}$ & -0.003 & $-0.02 * *$ \\
\hline & $(0.275)$ & $(0.035)$ & $(0.602)$ & $(0.041)$ \\
\hline \multirow[t]{2}{*}{ MAL } & $0.045^{* * *}$ & $-0.015^{* *}$ & $0.018 * * *$ & 0.002 \\
\hline & $(0.007)$ & $(0.046)$ & $(0.003)$ & $(0.534)$ \\
\hline \multirow[t]{2}{*}{ MYAN } & 0.006 & $-0.06^{* *}$ & -0.004 & $-0.02 * *$ \\
\hline & $(0.291)$ & $(0.035)$ & $(0.367)$ & $(0.041)$ \\
\hline \multirow[t]{2}{*}{ PHIL } & $0.024 * *$ & $-0.036^{* *}$ & $0.005^{* *}$ & $-0.015 * *$ \\
\hline & $(0.029)$ & $(0.045)$ & $(0.034)$ & $(0.031)$ \\
\hline \multirow[t]{2}{*}{ THAI } & $0.043^{* *}$ & $-0.017^{* *}$ & $0.009^{* *}$ & $0.011^{* *}$ \\
\hline & $(0.018)$ & $(0.023)$ & $(0.043)$ & $(0.037)$ \\
\hline \multicolumn{2}{|c|}{ Number of observations } & & 144 & \\
\hline \multicolumn{2}{|c|}{$\mathrm{p}$-value for the F-test of the model } & & 0.000 & \\
\hline \multicolumn{2}{|c|}{ Average RMSE } & & 0.098 & \\
\hline \multicolumn{2}{|c|}{$\mathrm{p}$-value for $\mathrm{AR}(1)$} & & 0.298 & \\
\hline \multicolumn{2}{|c|}{$\mathrm{p}$-value for $\mathrm{AR}(2)$} & & 0.425 & \\
\hline \multicolumn{3}{|c|}{$\mathrm{p}$-value for heteroskedasticity (White) test } & 0.396 & \\
\hline
\end{tabular}

Note: $*, * *$, and $* * *$ denote significance levels of $10 \%, 5 \%$, and $1 \%$ respectively. The $\mathrm{p}$-values are in parentheses.

Panel (4a) reveals that Vietnamese tourism endures slightly less cyclone damages than the average for SEA. Considering that the number of cyclones landed in Vietnam is more than twice the average in SEA, this is an encouraging result. The effect of cyclone damages in Thailand is about the same as the average; those in Laos and Cambodia are much less than average and only weakly significant, whereas those in 
Indonesia, Malaysia, and Myanmar are all clearly below the average. The Philippines suffers the heaviest losses (more than twice the average for SEA).

Panels (4b) shows that cyclone damages due to unsustainable tourism in Vietnam are also slightly lower than the average; those for Cambodia, Indonesia, Laos, and Myanmar are slightly higher than the average, whereas those for Malaysia and Thailand are about the average. The damages in the Philippines are again much higher than the average for SEA.

Panel (4c) demonstrates that the effects of cyclone damages on per capita income are smaller than those on tourism for all of the SEA countries. These results imply that most countries have made efforts to reinvest in new capital and infrastructure after a cyclone strikes, or to redirect their resources to other sectors in the economy so that these resources can be used more efficiently.

\section{Policy suggestions and conclusion}

Based on the estimated results, the following policies can be implemented to foster sustainable tourism and reduce the cyclone damages.

First, encourage tourists to practice responsible uses of resources during their stays in a hotel, such as turning off air conditioners when they go out, turning on fans in addition to air conditioners when they are in hotel rooms, and avoiding continuously running water in bathrooms, especially at washstands. Extra charge might be imposed beyond a certain level of usage as a preventive measure.

Second, increase the uses of other transportation modes other than private cars or motorcycles, such as busses, trolleys, subways, bicycles, and walking streets to reduce air pollution.

Third, impose fines to individual tourists or organizations engaging in any activity that causes deforestation, the number-one cause of increasing cyclone damages due the flash floods after a cyclone strikes.

Fourth, encourage reforestation to block high wind and reduce land erosion that increases the level of flash floods after a cyclone makes its landfall.

Finally, prevent disorganized urbanization due to excessive development of new tourist facilities that increases deforestation, traffic jams, environmental pollution, solid wastes, and 
contributes further to greenhouse-gas emissions that raise the air temperature and increase the cyclone-damage levels.

In sum, this paper shows that there is a two-way causality where cyclone damages reduce tourist arrivals, which in turn exacerbate the cyclone-damage levels due to unsustainable tourism. Hence, it is crucial to practice the aforementioned policies for sustainable tourism in order to mitigate the impacts of cyclones on economic development.

Similar to any empirical research, better data will yield more reliable results. Ideally, one can repeat the exercises with data on tourist expenditures, which are only available for the period of 2003-2013 at this moment. Hence, the lack of comprehensive data on tourist expenditures in addition to the data on tourist arrivals hinders a complete examination of the issue between cyclones and sustainable tourism. When tourist-expenditure data becomes available for a longer period, new estimations should be performed to obtain more comprehensive and precise results

\section{References}

Bender, M. A., Knutson, T. R., Tuleya, R., Vecchi, G. A., Sirutis, J. J., Garner, S. T., \& Held, I. M. (2010). Modeled impact of anthropogenic warming on the frequency of intense Atlantic hurricanes. Science, 327(5964), 454-458.

Bluedorn, J. C. (2005). Hurricanes: Intertemporal trade and capital shocks (Nuffield College Economics Paper 2005-W22).

Bond, S. R. (2002). Dynamic panel data models: A guide to micro data methods and practice (CEMMAP Working Paper, CWP09/02). London, UK: Centre for Microdata Methods and Practice.

Chang, C. H. (2010). The impact of global warming on storms and storm preparedness in Southeast Asia. Kajian Malaysia, 28(1), 53-76.

Coffman, M., \& Noy, I. (2009). Hurricane Iniki: Measuring the long-term economic impact of a natural disaster using synthetic control (University of Hawaii Economics Working Paper 09-05). HI: University of Hawaii Economics.

Emanuel, K. (2005). Increasing destructiveness of tropical cyclones over the past 30 years. Nature, 4, 686688.

Estrada, F., Botzen, W. J., \& Tol, R. S. J. (2015). Economic losses from US hurricanes consistent with an influence from climate change. Nature Geoscience, 8, 880-884.

Granvorka, C., \& Strobl, E. (2010). The impact of hurricanes strikes on the tourism in the Caribbean (UWI Conference Paper). Retrieved from http://sta.uwi.edu/conferences/09/salises/ documents/C\%20Granvorka.pdf 
Hershberger, M. (2014). Six environmental challenges facing Southeast Asia. Retrieved from http://matadornetwork.com/change/6-environmental-challenges-facing-southeast/

Hitchcock, M., King, V. T., \& Parnwell, M. (eds.) (2010). Tourism in Southeast Asia: Challenges and new directions. HI: University of Hawai' $i$ Press.

IMF. (2015). IMF finances. Retrieved from http://www.imf.org/data/imf-finances

Joint Typhoon Warning Center. (2015). Annual tropical cyclone reports. US National Climatic Data Center, National Oceanic and Atmospheric Administration. Retrieved from https://www.ncdc.noaa.gov/data-access

Kennedy, P. (2008). A guide to econometrics (6th ed.). MA: MIT Press.

Knutson, T. R., Sirutis, J. J., Garner, S. T., Held, I., \& Tuleya, R. (2007). Simulation of the recent multidecadal increase of Atlantic hurricane activity using an 18-km-grid regional model. American Meteorological Society BAMS, 1549-1565.

Le, T. (2014). Sustainable tourism: A balancing act. Retrieved from http://www.aseannews.net /sustainable-tourism-a-balancing-act/

Mazumder, M. N. H., Sultana, M. A., \& Al-Mamun, A. (2013). Regional tourism development in Southeast Asia. Transnational Corporations Review, 5(2), 60-76.

Mendelsohn, R., Emanuel, K., Chonabayashi, S., \& Bakkensen, L. (2012). The impact of climate change on global tropical cyclone damage. Nature Climate Change, 2, 205-209.

Michaels, P. J., Knappenberger, P. C., \& Davis, R. E. (2006). Sea-Surface temperatures and tropical cyclones in the Atlantic basin. Geophysical Research Letters, 33, 1-4.

Ponnudurai, P. (2015). Climate change conjures up 'alarming' scenarios in Southeast Asia. Retrieved from http://www.rfa.org/english/commentaries/east-asia-beat/climate-change- 07022013165938. html

Skidmore, M., \& Toya, H. (2002). Do natural disasters promote long-run growth? Economic Inquiry, 40(4), 664-687.

Strobl, E. (2008). The macro-economic impact of natural disasters in developing countries: Evidence from hurricane strikes in the Central American and Caribbean region. Retrieved from http://chaire-edfddx.polytechnique.fr/servlet/com.univ.collaboratif.utils.LectureFichiergw?ID_FICHIER=126294522 8957\&ID_FICHE=13021.

US Department of Agriculture. (2015). International macroeconomic data set. Retrieved from http://www.ers.usda.gov/data-products/international-macroeconomic-data-set.aspx

World Bank Group. (2015). International tourism, number of arrivals. Retrieved from http://data.worldbank.org/indicator/ST.INT.ARVL?page=3 